\title{
Combined Action of Resveratrol and Carnosol on Down Regulation of NF-кB: A Computational Study
}

\author{
Madhusudana Pulaganti ${ }^{1}$, Anuradha Chevva Moremmagari ${ }^{2}$, Chitta Suresh Kumar ${ }^{1^{*}}$ \\ ${ }^{1}$ BIF, Dept of Biochemistry, Sri Krishnadevaraya University, Anantapur, India \\ ${ }^{2}$ Dept of Biotechnology, Sri Krishnadevaraya University, Anantapur, India
}

Corresponding author: Dr. Chitta Suresh Kumar, Dept of Biochemistry, Sri Krishnadevaraya University, Anantapur-560 003 India, Tel: +91-8554-255466; Fax:+91-8554-255466; E-mail: chitta34c@gmail.com

\begin{abstract}
Carnosol and resveretrol are two natural compounds with potent antioxidant activity. These two are at various stages of research independently on various types of cancer. Till the time many of researchers used carnosol and resveretrol for cancer comprehensiveness by targeting NF- $\kappa \mathrm{B}$. But the combinational use of compounds in research is limited, at present number of researchers are focusing on combinational use of compounds in research towards the increase in rate of success in control of various diseases. In this manuscript we made an attempt to down regulate the $\mathrm{NF}-\kappa \mathrm{B}$ progression in anti-apoptotic signals with carnosol and resveratrol. Various bioinformatics tools have been used including Autodock4.0, HEX, PROCHECK, PROSA, WHAT-IF etc. As per our findings P50 monomer has best binding interaction with carnosol by providing negative charge of $-6.15 \mathrm{~K} \mathrm{cal} / \mathrm{mol}$, than that of binding charge of resveretrol having - 1.5 $\mathrm{K} \mathrm{cal} / \mathrm{mol}$. Similarly in case of p65 the binding charges of carnosol and resveretrol are $-3.10 \mathrm{~K} \mathrm{cal} / \mathrm{mol}$ and $-0.89 \mathrm{~K} \mathrm{cal} / \mathrm{mol}$ respectively indicates that $\mathrm{p} 65$ has less affinity than that of p50 towards carnosol. Similar we workout on p65-p50 $(\mathrm{NF}-\kappa \mathrm{B})$ dimer and with complex docking with DNA. We noticed when monomers escaped in binding, carnosol and resveratrol complex has more affinity to get bind with p65-p50 dimer with total binding energy of -9.73 . Finally we find out the order of inhibition of p65-p50 resveretrol-carnosol complex when docked with DNA. This clearly showed that use of combinational phytophenols may decrease the dose of natural phytophenols and increase the potency of their activity.
\end{abstract}

Received Date: October 14, 2015
Accepted Date: December 24, 2015
Published Date: December 30, 2015

Citation: Kumar, C.S., et al. Combined Action of Resveratrol and Carnosol on Down Regulation of NF-kB: A Computational Study. (2015) Bioinfo Proteom Img Anal 1(2): 56- 64.

DOI: $10.15436 / 2381-0793.15 .015$

Keywords: NF-kB; Carnosol; Resveratrol; AUTODOCK 4.0; HEX; PROCHECK; WHAT IF; PROSA2003

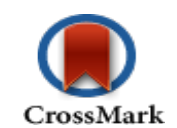

\section{Introduction}

Carnosol (Figure 1) is a naturally occurring phytopolyphenol found in Rosemary officinalis. Its herbs and oils are commonly used as a spice and flavoring agents in food processing due to its desirable flavor and high antioxidant activity ${ }^{[1]}$. Carnosol has been evaluated for anti-cancer property in prostate, breast, skin, leukemia, and colon cancer with promising results. These studies have provided evidence that carnosol targets multiple deregulated pathways associated with inflammation and cancer that include nuclear factor kappa B (NF- $\mathrm{B}$ ), apoptotic related proteins, phosphatidylinositol-3-kinase (PI3 K)/Akt, androgen and estrogen receptors, as well as molecular targets. In addition, carnosol appears to be well tolerated in that it has a selective toxicity towards cancer cells versus non-tumorigenic cells and is well tolerated when administered to animals ${ }^{[2]}$.
Resveratrol (3,5,4'-trihydroxy-trans-stilbene) (Figure 1) is a stilbenoid, a type of natural phenol, and a phytoalexin produced naturally by several plants when under attack by pathogens such as bacteria or fungi. Resveratrol is also found in the skin of red grapes and in other fruits. Resveratrol has also been produced by chemical synthesis ${ }^{[3]}$ or by biotechnological synthesis (metabolic engineered micro-organisms) ${ }^{[4]}$ and is sold as a nutritional supplement derived primarily from Japanese knotweed. In mouse and rat experiments, anti-cancer, anti-inflammatory, blood-sugar-lowering and other beneficial cardiovascular effects of resveratrol have been reported. These results have yet to be replicated in humans. 


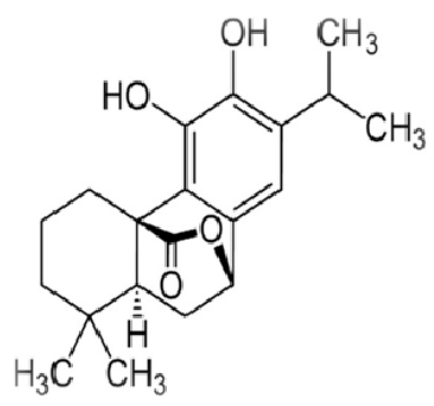

Carnosol

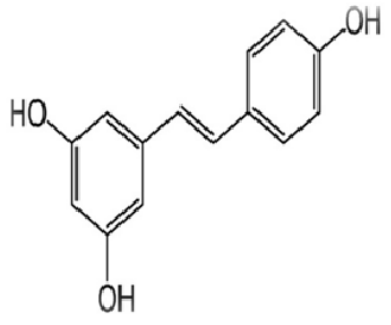

Resvaratrol
Figure 1: Structures of Carnosol and Resvaratrol

There is a profound need to explore and identify the anti-cancer properties of these two (carnosol, resvaretrol) medicinal herbs. These two compounds (carnosol, resvaretrol) have under various phases of research in individually. But the results are not satisfactory in their unique actions with high doses. Now our experiment could expect to limit the high dose criteria of these photochemical and more efficacy by combined action in rat models for cancer comprehensiveness.

Breast cancer is the third most common tumor in the world and represents $9 \%$ of the global cancer burden. This percentage varies considerably around the world: in high-risk areas, such as North America and western Europe, breast cancer accounts for one in four female cancers, while in low-risk areas such as China and Japan, it accounts for only one in eight to one in 16. The importance of environmental factors in the etiology of breast cancer is demonstrated by the change in risk in migrant populations. Risks factors include family history, high fat diet, early age of menarche, nulliparity and late age of menopause. In India one study saying that, in the city of Bombay there is an alarming rise of cases of breast cancer in women. It will double by 2025 . An average of 1,300 cases was recorded in Mumbai every year between 2001 and 2005. According to a study by Tata Memorial Hospital, where population-based Mumbai Cancer Registry data was studied in women between the age group of 25 and 74, it was observed that cases of breast cancer have been increasing among older women (above 50 years) than the younger age group ${ }^{[5]}$.

$\mathrm{NF}-\kappa \mathrm{B}$ is able to induce several of cellular alterations and has been shown to be constitutively activated in many types of cancer cells. There are several mechanisms by which NF- $\kappa \mathrm{B}$ transcription factors are uncoupled from their normal modes of regulation, and these have been associated with cancer. Constitutively activated NF- $\mathrm{BB}$ transcription factors have been associated with several aspects of tumorigenesis, including promoting cancer-cell proliferation, preventing apoptosis and increasing a tumors angiogenic and metastatic potential. NF- $\kappa \mathrm{B}$ site is present within the cyclin D1 promoter ${ }^{[6]}$ and there is strong evidence that NF- $\kappa$ B dependent cyclin D1 is over-expressed in breast cancers. Leukemia and lymphoma-cancers of the bone marrow and lymph nodes respectively are caused by uncontrolled proliferation of blood cells. Numerous studies have documented elevated or constitutive NF- $\kappa$ B DNA binding activity both in mammary carcinoma cell lines and primary breast cancer cells of human and rodent origin ${ }^{[7,8]}$. Here we focused on the interactions of NF$\kappa \mathrm{B}$ with carnosol and resveratrol both independently and combinational by molecular docking interaction studies. This can be achieved by using various computational tools and techniques. The independent binding energies of carnosol and resveretrol with NF- $\kappa B$ showed effective inhibition energies further it may inhibit the activation of $\mathrm{NF}-\kappa \mathrm{B}$ as per the literature it is also evidenced. As of thought use of combination of these two may enhance the binding energies to NF- $\kappa \mathrm{B}$ due to different binding sites and also decreases the criteria of high dose in use of phytochemicals. This clearly urges the scope for combinational natural drug research for cancer comprehensiveness.

\section{Methods}

In present work all the calculations were carried out with high frequency computational analysis such as molecular modeling, energy minimizations, design and optimization of lead molecules, protein ligand interaction studies by molecular docking, dynamics etc., in Hi-end server (Pentium IV 3.4 MHzs, AMD Athlon 64 bit, Dual processor with1GB RAM) manufactured by HCL Corporation, Pondicherry, India was used. Most of the software used was either Windows or Linux flat form based which were well accepted and referred in various publications at high rated research journals. Academic license was obtained for the commercial software used in the present study by requesting the concerned suppliers. The software used in the present study a PyMOL (http://www.delanoscientific.com/), Autodock-Tool (http://autodock.scripps.edu//9], National Center for Biotechnology Information (NCBI) (www.ncbi.nlm.nih.gov/), Protein Data Bank (PDB) (www.rcsb.org/pdb), PROCHECK, ProSA-web ${ }^{[10]}$ (http://prosa.services.came.sbg.ac.at), What-if , PDBSUM ${ }^{[11]}$ (http://www.ebi.ac.uk/pdbsum/), ADME tox Server: https:// ilab.acdlabs.com/iLab2/index.php\#), PRODRG (www.davapc1. bioch.Dungee.ac.uk), HEX Docking Server.

\section{Preparation of files for docking}

PDB file for docking are prepared by editing retrieved mouse NF- $\kappa$ B structure from RCSB(PDB-1VKF). Resvaratrol and Carnosol were designed by using PRODRG server ${ }^{[12]}$ and partial charges were added and saved as pdb files. The compounds were then tested for Lipinski's Rule of Five using the Molinspiration server (http://www.molinspiration.com/). ADME toxicity of carnosol and resveretrol were predicted in ADMEtox server.

Docking of p50, p65 monomers with carnosol and resveretrol independently: AutoDock 4.0 (ADT) was used for the docking interactions of carnosol and resveretrol molecules on to the mouse p50, p65, monomers ${ }^{[13]}$. In order to run ADT, to the PDB files of Mouse p50, p65, monomers, the histidine hydrogens as well as polar hydrogens were added and the $\mathrm{C}$ - and N-terminal ends were charged and the Kollman united atom partial charges were assigned. Furthermore the atomic salvation parameters were assigned and were saved in pdbqt format. Carnosol and resveretrol pdbqt file was obtained from PRODRG Server. All the atom types were checked in the carnosol and resveretrol and modified when needed. Carnosol and resveretrol were chosen charged and hydrogens were added in order to fill all empty valences, and the Gasteiger charges were calculated for the atoms, and were then saved. In order to run AutoDock, grid maps have to be calculated. This was done by using the module AutoGrid, for carnosol and with the same parameters: number of grid points 
in $\mathrm{X}, \mathrm{Y} \& \mathrm{Z}$ were taken as default as $40 \mathrm{X} 40 \mathrm{X} 40$ (this covers the active site extensively and let the carnosol move without any constraints regarding the box size), spacing between grid points, $0.375 \AA$ and a common grid centre. The grid centre was chosen slightly of the centre axis of the active site in order to avoid any symmetry problems that might arise. In docking matrix the docking parameter files (dpf) were generated by a Python script that uses the methods in AutoDock. The script takes one pdbqt file, loops over the pdbqt files and sets the name of the maps and the carnosol in the parameter file. It also sets the Lamarckian genetic algorithm (LGA) to be used with a population size of 150 individuals. Thus 150 individuals were calculated at 100 different runs (i.e. 100 dockings) and the runs had two stop criteria: a maximum of 2,500,000 energy evaluations or a maximum of 27,000 generations. The carnosol and resveretrol were set to start in a random position and conformation, the translations were set to have a maximum of $2 \AA /$ step and the quarterion and the tortion both had a maximum at $50 \%$ step. The elitism number was set to 1 . The mutation rate and the crossover rate were 0.02 and 0.80 respectively. The probability that an individual in the population will undergo a local search was set to 0.06 and the constraint used in the pseudo- solis and wets local search was set to a maximum of 150 iterations per search. The maximum number of successes or failures before changing rho in the local search method was both set to 4 . The size of the local search space was set 1.0 and the smallest step the local search could take before ending was set to 0.01 . These standardized docking parameters create a file for each ligand and hence AutoDock program for each ligand was run. Using the hardware as mentioned in earlier section, one run (a Docking) took between 7 and 30 minutes depending on the complexity of the Carnosol, number of rotatable and number of atoms. Docking results in graphical presentation were analyzed by using PMV (Python Molecular Viewer) 1.4.5.

Docking of NF-кB with carnosol and resvaratrol: Here we used same parameter set like mentioned above but instead of monomers here we used heterodimer (p50-p65). In Autodock4.2 suit docking has been done and DLG files are analyzed.

\section{Complex docking with DNA}

For complex docking we took the docked complex dock log files (DLG) generated from Autodock of p50-p65 heterodimer with carnosol and resveretrol further subjected in HEX server for complex docking with DNA.

DNA docking with NF-кB-RESL-CAR complex: Complex docking analysis predicts the binding of resveretrol and carnosol at DNA binding pocket of NF- $\mathrm{BB}$. The resveretrol- carnosol complex suggested to bind in the area occupied by the major groove at the site of a DNA binding regions, this binding mode of resveretrol carnosol complex would significantly interfere with the binding to DNA. In the presence of resveretrol carnosol complex a decrease in the protein-DNA complex are observed. We have to be tested this prediction in gel shift assays in the absence and presence of resveretrol-carnosol complex.

\section{Results}

This study was targeted and predicted the stable confirmations of monomers and heterodimers of p50-p65 (NF- $\mathrm{BB})$ with natural compounds carnosol and resveratrol both in combination and independent docking interactions. This is novel approach for development of anti-cancer drugs as per published literature.

The pdb file of mouse p65/p50 (PDB-1VKX) (Chen FE et al., 1998) homo and heterodimers in complex with DNA are retrieved from Protein Data Bank (PDB). Figure 2 shows the schematic representation of DNA interation with NF- $\kappa \mathrm{B}$ [chain A (p65); Chain B (P50)]. The co-crystallized DNA macromolecule was removed from the structure. P65-p50 hetero dimers and p50, p65 monomers (chains A and B) were selected, saved in PDB format for further validation, docking and dynamics simulations prepared using the graphical interface Maestro. The saved Protein Data Bank crystal structures are edited. All water molecules were removed, the hydrogen atoms were added to the proteins and all atom force field (OPSL-2001) charges and atom types were assigned.

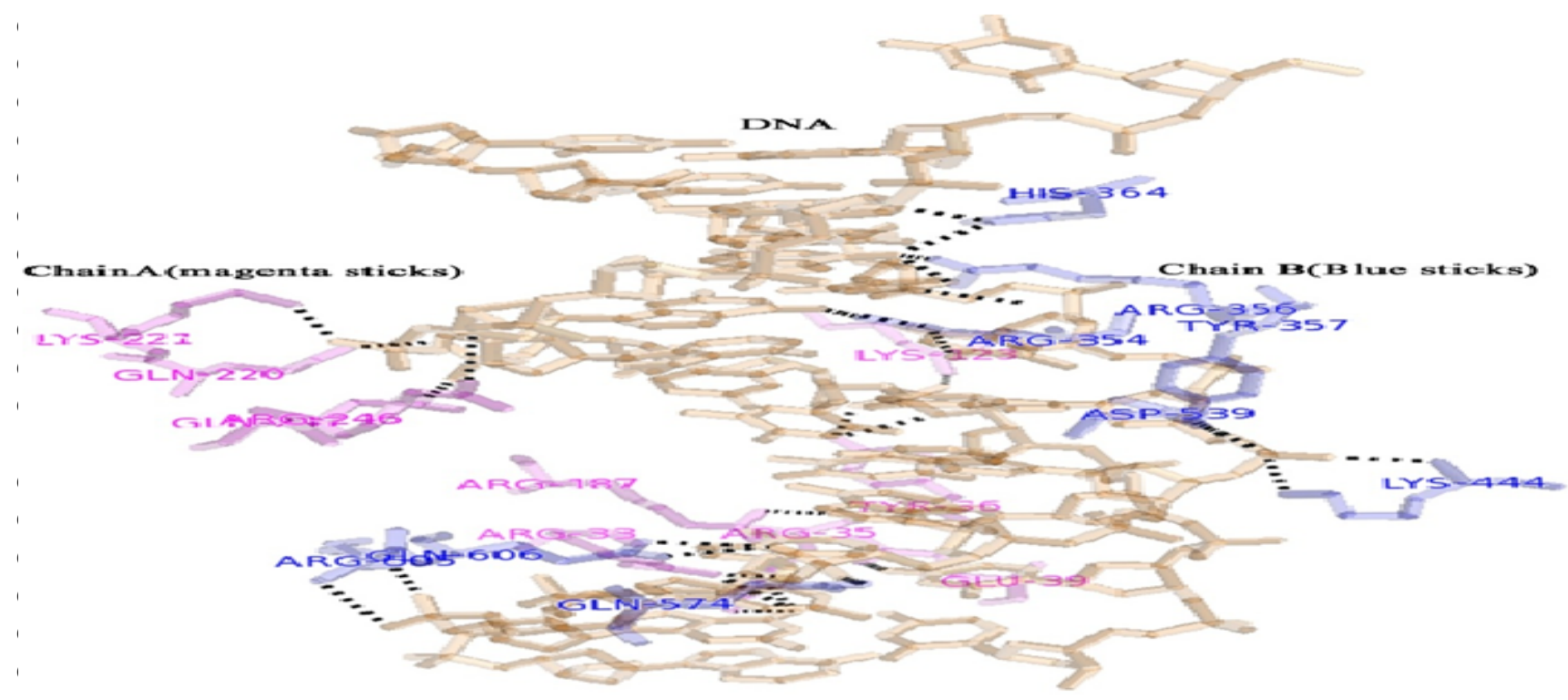

Figure 2: Schematic representation of DNA interation with NF- $\kappa B$ [chain A (p65); Chain B (P50)] 


\section{p50, p65 mono and p50-p65 heterodimer refinement}

The edited Protein data bank file models may have some sources of errors. It is important, therefore, to have an assessment of structure's quality and to be able to identify regions that may need modifications especially at protein folding and turns. The aim of model evaluation is to determine whether the model is acceptable and suitable to use for molecular analysis such as docking and dynamics. This clearly judges the accuracy of model. The PROCHECK suite of programs provides a detailed check on the stereochemistry of a protein structure and it was explained by using Ramachandran plot ${ }^{[14]}$. The protein structure of mouse p50, p65 mono and p50-p65 heterodimers are verified by PROCHECK, has given $69.8 \AA$ in favorable regions, 25.6 in allowed regions, 3.6 generously allowed regions and 1.0 in disallowed regions (Figure 3), Plot statistics were shown in (Table 1) According to all these statistics mouse p50, p65 mono and heterodimers were acceptable structure for further step. Packing quality of the models was investigated by the calculation of WHAT-IF Quality Control value ${ }^{[15]}$.
From What if analysis shows that RMS Z-score values for bond lengths and angle parameters for p50, p65 mono and heterodimer models are $-0.232,-0.145$, and -0.186 , respectively, these are within the typical of highly refined structures in (Figure 4). The fact that the RMS Z-score values of bonding distances and angles for the crystal structures are small might indicates that too-strong constrains for models. ProSA-web is a tool widely used to check 3D models of protein structures for potential errors $^{[10]}$. The final structural models of mouse p50, p65, mono and heterodimers were tested with the ProSa web program by examining whether the interaction of each residue with the remainder of the protein is maintained favorable. As shown in (Figure 5a), the $\mathrm{Z}$ - score for mouse p50, p65 mono and heterodimers is above -5.0 of crystal structures. ProsA-web analysis had showed that overall the residue energies of the mouse p50, p65 mono and heterodimers (Figure 5b) remains negative for almost all amino acid residues except for some peaks in the starting region, indicating the acceptability of the edited pdb model.
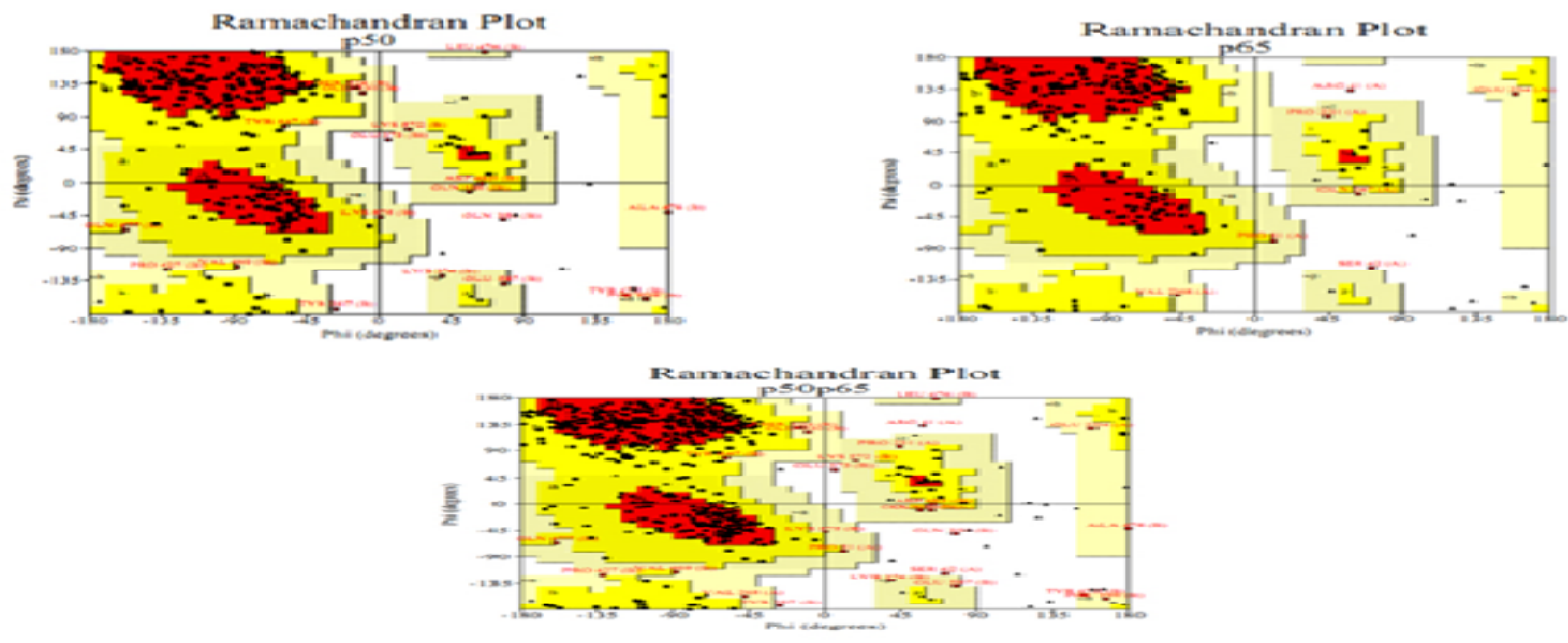

Figure 3: Ramchandran plots of p50, p65 mono and heterodimers in PROCHECK.

Table 1: Ramachandran plot statistics for best models of mouse p50, p65 protein structures (PROCHECK)

\begin{tabular}{|c|c|c|c|c|c|c|}
\hline \multirow{2}{*}{ Ramachandran plot statistics } & \multicolumn{2}{|l|}{ P50 } & \multicolumn{2}{|c|}{ P50-p65 } & \multicolumn{2}{|l|}{$\mathbf{P 6 5}$} \\
\hline & Residues & $\%$ & Residues & $\%$ & Residues & $\%$ \\
\hline Residues in most favoured regions & 187 & 69.8 & 458 & 85.4 & 160 & 69.9 \\
\hline Residues in additional allowed regions & 63 & 23.5 & 74 & 13.8 & 64 & 27.9 \\
\hline Residues in generously allowed regions & 15 & 5.6 & 4 & 0.7 & 3 & 1.3 \\
\hline Residues in disallowed regions & 3 & 1.1 & 0 & 0.0 & 2 & 0.9 \\
\hline Number of non-glycine and non proline residues & 268 & 100 & 536 & 100 & 229 & 100 \\
\hline Number of end-residues (excl. Gly and Pro) & 1 & & 2 & & 2 & \\
\hline Number of Glycine residues (shown as traingle) & 26 & & 54 & & 18 & \\
\hline Number of proline residues & 17 & & 34 & & 24 & \\
\hline Total number of residues & 312 & & 626 & & 273 & \\
\hline
\end{tabular}



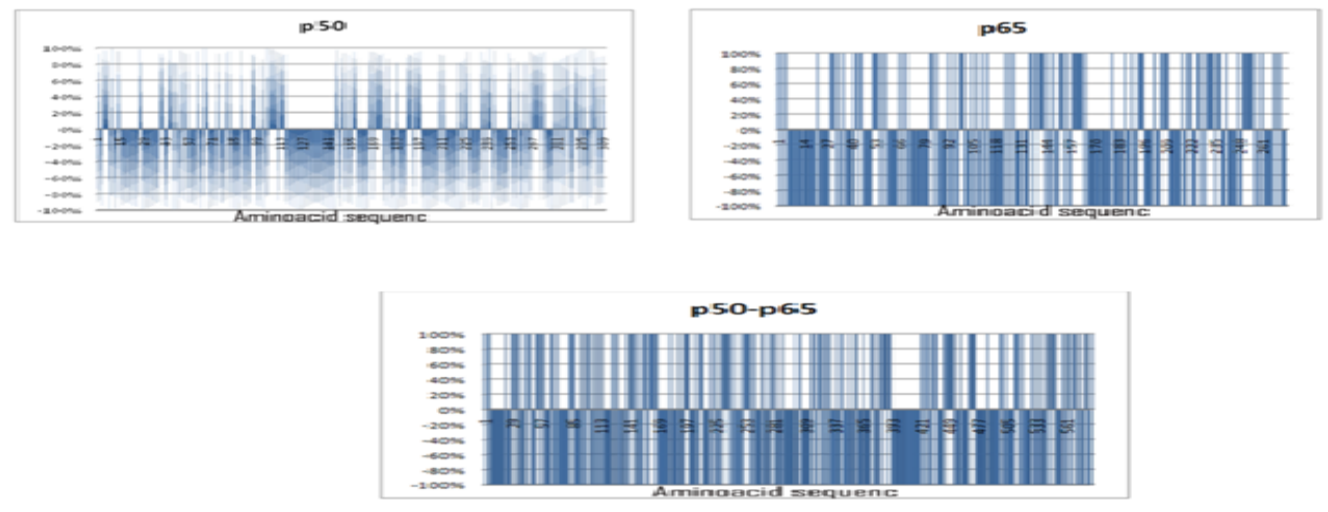

Figure 4: Fine packing quality graphs of p50, p65 mono and heterodimers in what-if.
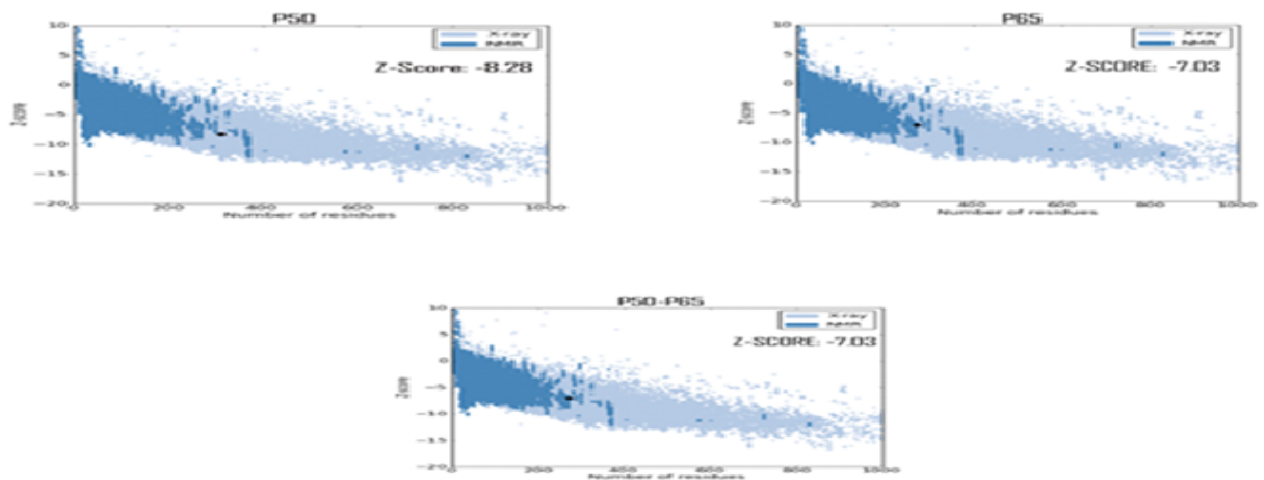

Figure 5a: Overall model quality graphs (Prosa) of p50, p65 mono and heterodimers, showing negative values. 3
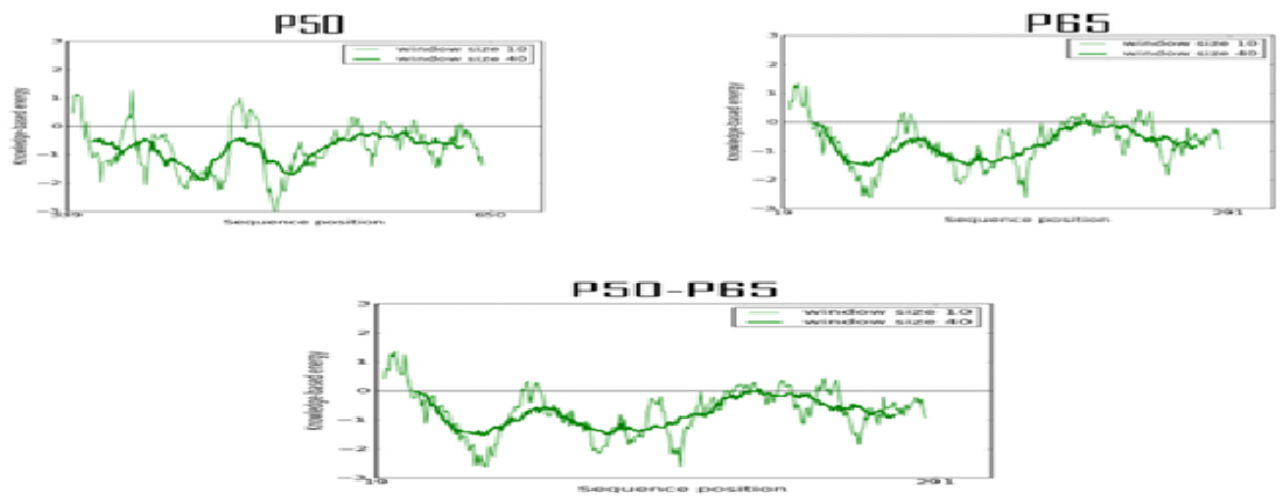

Figure 5b. Local model quality graphs (Prosa) of Mouse p50, p65 mono and heterodimers, showing negative regions.

ADME/Tox: properties of Carnosol and Resvaratrol: ADME and toxicity predictions were carried out with an objective to understand their pharmacokinetic and safety profiles. This was done with the ADME/Tox web-box v3.5 tool available online. The in-silico ADME/toxicity prediction data are shown in (Table 2). Carnosol and resvaratrol showed a pKa for the basic group around "0" and for the acidic group also "0" suggesting that these compounds come under zwitter ions (Carnosol and resvaratrol). The aqueous solubility (Logsw) of Carnosol and resvaratrol are $0.015 \mathrm{mg} / \mathrm{ml}$ and $1.5 \mathrm{mg} / \mathrm{ml}$ respectively. Logsw provide the quantitative estimation of the compounds solubility in pure water at $25^{\circ} \mathrm{C}$ using fragmental GALAS (Global, Adjusted Locally Acording to Similarity) model. These methodologies allow the model to provide a quantitative assessment of the quality of each predication in form of Reliability Index Value (RI). The Reliable aqueous solubility of compounds is higher than $0.5 \mathrm{RI}$. It represents these compounds are soluble in aqueous environment and even $\log \mathrm{D}$ or $\log \mathrm{P}$ data also suggest that these molecules have adequate aqueous solubility. The module LogS simulates the full solubility-pH profile. Initially, this list is populated by the solubility predictions at physiologically relevant $\mathrm{pH}$ conditions; Carnosol and resvaratrol are the range from -2.05 to -4.09 . The human oral bioavailability for new compounds is identified by using a combination of two methods- probabilistic and mechanistic. First, the mechanistic part of the module tries to evaluate the query compound with regard to several crucial bioavailability limiting factor: solubility in stomach or intestine, stability in acidic medium, intestinal membrane permeability by passive or active transport. All those properties are predicted using independent algorithms, and experimental data sets. The results demonstrate that Carnosol and resvaratrol have the maximum oral bioavailability of less than $50 \%$. The property of average plasma protein binding (\%PPBS) of Carnosol and resvaratrol was found to 
be $70.97-88.10 \%$. These drugs would predominantly bind less bound to alpha1-acid glycoprotein, albumin and lipoproteins. The low binding affinity of Carnosol and resvaratrol with blood serum protein, the more efficiently it can transfer into cell membranes or diffuse.

Table 2: In-silico pharmacokinetic / toxicity predictions of carnosol and resvaratol by ADME/Tox:

\begin{tabular}{|c|c|c|c|c|c|c|c|c|c|c|c|c|}
\hline \multirow[t]{2}{*}{ Compound } & \multicolumn{2}{|l|}{ Solubility } & \multicolumn{4}{|c|}{$\begin{array}{l}\text { Physico-Chemical Determi- } \\
\text { nants }\end{array}$} & \multirow{2}{*}{$\begin{array}{l}\text { \% Oral } \\
\text { bioavail- } \\
\text { ability }\end{array}$} & \multicolumn{2}{|c|}{ Distribution } & \multirow{2}{*}{$\begin{array}{l}\text { Geno- } \\
\text { toxicity } \\
\text { Ames } \\
\text { test }\end{array}$} & \multirow{2}{*}{$\begin{array}{l}\text { Acute tox- } \\
\text { icity LD } \\
\text { Mouse } \\
\text { (mg/kg) } \\
\text { Oral }\end{array}$} & \multirow{2}{*}{$\begin{array}{l}\text { Acute } \\
\text { toxicity } \\
\text { LD }_{50} \text { Rat } \\
\text { (mg/Kg) } \\
\text { Oral }\end{array}$} \\
\hline & $\begin{array}{l}\text { Water } \\
\text { (LogSw) }\end{array}$ & $\begin{array}{l}\text { Buffer } \\
\text { (pH 7.4) } \\
\text { LogS }\end{array}$ & $\log D$ & $\log P$ & $\begin{array}{l}\text { Pka } \\
\text { (Acid) }\end{array}$ & $\begin{array}{l}\text { Pka } \\
\text { (Base) }\end{array}$ & & $\begin{array}{l}\text { Plasma } \\
\text { Protein } \\
\text { Binding }\end{array}$ & $\begin{array}{l}\text { Vd }(\mathbf{L} / \\
\mathbf{K g})\end{array}$ & & & \\
\hline RESVERATROL & -2.19 & -2.05 & 2.59 & 2.59 & 9.40 & ---- & $<70 \%$ & $70.97 \%$ & 1.84 & 0.2 & 920 & 870 \\
\hline CARNOSOL & -4.33 & -4.09 & 4.4 & 4.4 & 9.7 & ---- & $<50 \%$ & $88.10 \%$ & 2.54 & 0.14 & 1200 & 1600 \\
\hline
\end{tabular}

\section{Docking Analysis of resveretrol and carnosol with p50, p65 and NF-кB}

To understand mechanism of action of resveretrol and carnosol at molecular level we performed docking of resveretrol and carnosol independently onto p50, p65 and NF- $\kappa$ B. The predicted binding affinities of resveretrol on p50, p65 and NF- $\mathrm{B}$ by in-silico screening methodology showed excellent correlation with the experimental results ${ }^{[16,17]}$ and similarly for carnosol also. The 100 docking conformations for resveretrol and carnosol were divided into groups according to a $1.0 \mathrm{z}^{\circ} \mathrm{A}$ RMSD criterion by using the clustering module in ADT. Besides RMSD clustering, AutoDock also uses binding free energy evaluation to identify the best binding mode. Energy items calculated by AutoDock4 include intermolecular energy (constituted by vanderwaal's energy, hydrogen bonding energy, desolvation energy, and electrostatic energy), internal energy, and torsion energy. The energy information is listed in (Table 3), and the interaction modes of resveretrol and carnosol are shown in (Figures 7a. and 7b).

Table.3: Docking interactions of carnosol and Resveratrol with Monomers and dimers of p50, p65 in Autodock4

\begin{tabular}{|c|c|c|c|c|c|c|c|c|c|}
\hline No. & Protein & Compound & RMSD $^{a}$ & $\begin{array}{l}\text { Binding Energy } \\
\text { (Kcal/Mol) }\end{array}$ & $\begin{array}{l}\text { Inhibition } \\
\text { Constant }{ }^{\mathrm{c}}(\mathrm{Ki}) \\
(\mu \mathrm{M})\end{array}$ & $\begin{array}{l}\text { Final Intermo- } \\
\text { lecular energy } \\
\text { (kcal/mol) }\end{array}$ & $\begin{array}{l}\text { Amino acid } \\
\text { involved in } \\
\text { interaction }\end{array}$ & $\begin{array}{l}\text { No of } \\
\text { Hydrogen } \\
\text { bonds }\end{array}$ & $\begin{array}{l}\text { Bond } \\
\text { length }\end{array}$ \\
\hline 1. & P50 & $\begin{array}{l}\text { Carnosol } \\
\text { Resveratrol }\end{array}$ & $\begin{array}{l}0.0 \\
0.0\end{array}$ & $\begin{array}{l}-6.15 \\
1.5\end{array}$ & $\begin{array}{l}31.07 \\
--\end{array}$ & $\begin{array}{l}-6.33 \\
0.0\end{array}$ & $\begin{array}{l}\text { Val358. His409 } \\
\text { Ser410,His409 }\end{array}$ & $\begin{array}{l}2 \\
2\end{array}$ & $\begin{array}{l}2.082 \\
1.92 \\
1.912\end{array}$ \\
\hline 2. & P65 & $\begin{array}{l}\text { Carnosol } \\
\text { Resveratrol }\end{array}$ & $\begin{array}{l}0.0 \\
0.0\end{array}$ & $\begin{array}{l}-3.10 \\
0.89\end{array}$ & $5.34 \mathrm{Mm}$ & $\begin{array}{l}-3.37 \\
-0.26 \\
\end{array}$ & $\begin{array}{l}\text { Ala242,Ser240 } \\
--\end{array}$ & $\begin{array}{l}2 \\
-- \\
\end{array}$ & $\begin{array}{l}2.801 \\
2.555 \\
\end{array}$ \\
\hline 3. & P50-P65 & $\begin{array}{l}\text { Carnosol } \\
\text { Resveratrol }\end{array}$ & $\begin{array}{l}0.00 \\
0.00\end{array}$ & $\begin{array}{l}-5.65 \\
-4.08\end{array}$ & $\begin{array}{l}72.74 \\
1.03 \mathrm{mM}\end{array}$ & $\begin{array}{l}-5.89 \\
-5.23\end{array}$ & $\begin{array}{l}\text { Gln247, Arg246, } \\
\text { Lys-218 } \\
--\end{array}$ & $\begin{array}{l}3 \\
--\end{array}$ & $\begin{array}{l}2.131 \\
2.03 \\
2.41 \\
2.16\end{array}$ \\
\hline
\end{tabular}

${ }^{a}$ Heavy atoms root-mean-square deviation with respect to the experimental structure.

${ }^{\mathrm{b}}$ The change in binding free energy is related to the inhibition constant using the equation: $\Delta \mathrm{G}=\mathrm{RT}$ in Ki, where $\mathrm{R}$ is the gas constant 1.987 cal K-1 mol-1, and T is the absolute temperature assumed to be $298.15 \mathrm{~K}$.

${ }^{\mathrm{c}}$ Estimated inhibition constant at $298.15 \mathrm{~K}$

Resveretrol majorly interact with p50 monomer of $\mathrm{NF}-\kappa \mathrm{B}, 4^{\prime} \mathrm{OH}$ atom of resveretrol interact with the $\gamma$-amino group of $\mathrm{Gln}^{606}$ (B) by forming a $3.2 \AA$ distance H-bond. $3 \mathrm{OH}$ atom of resveretrol interact with $\mathrm{NH} 1$ and NH2 amino groups of Arg ${ }^{605}$ (B) by forming a $3.8 \AA$ distance H-bonds. Over all, Contrary to most of the docking modes, the model for resveretrol shows the phenolic oxygen moieties is stacked to $\operatorname{Gln}^{606}(\mathrm{~B})$ and $\operatorname{Arg}^{605}(\mathrm{~B})$ of NF- $\mathrm{B}$, p50 monomer (Figure 7a). Carnosol interact with NH1 amino group of $\operatorname{Arg}^{246}(\mathrm{~A}), \varepsilon$-amino group of $\operatorname{Lys}^{218}(\mathrm{~A})$, and $\gamma$-amino group of $\mathrm{Gln}^{247}$ (A) by forming a less than $2.05 \AA \mathrm{H}$-bonds. The carnosol had more reactive groups in its structure; it forms four Hydrogen bond with " $\mathrm{A}$ " chains of NF- $\kappa \mathrm{B}$, The ranking of binding energies for resveretrol with p50, p65 and p65-p50, is - 1.5, - 0.8 and - 4.08 Kcal/mol respectively. This explains that resveretrol has more affinity to p50 than p65 but in case of p65-p50 it has much more affinity than that of monomers. Carnosol with p50, p65 and NF- $\kappa B$ showing maximum binding energies of $-6.15,-3.10$ and $-5.89 \mathrm{~K} . \mathrm{cal} / \mathrm{mol}$ respectively (Figure $7 \mathrm{~b}$ ). This explains that carnosol has more affinity to p50 than rest of the two. The polar contacts between the mouse p50, p65 with carnosol and resvaratrol have find represented in (Figure 6). Based on the polar contacts, total binding energies and inhibition constants of carnosol, resvaratrol were in table.3, we predict that, the binding modes of p50, p65 might be changed due to change in confirmations after binding with carnosol or resveretrol and there is unavailability of binding sites to themselves, finally there is no active complex formation $(\mathrm{NF}-\mathrm{\kappa B})(\mathrm{P} 50-\mathrm{P} 65)$, which may prevents the tumor formation and there is no anti-apoptotic signals for survival of cancer cells. Furthermore Autodock docking analysis also reveals that these resveretrol and carnosol can enter the DNA-binding region of $\mathrm{NF}-\kappa \mathrm{B}$. In the arrangements with the lowest docked energy, resveretrol and carnosol were sandwiched between the DNA binding residues $\operatorname{Arg}^{605}(\mathrm{~B}), \operatorname{Arg}^{246}(\mathrm{~A}), \mathrm{Gln}^{606}(\mathrm{~B}), \operatorname{Lys}^{218}(\mathrm{~A})$, and $\mathrm{Gln}^{247}(\mathrm{~A})$. The results indicate that the resveretrol and carnosol had more affinity to interact with the DNA binding site of NF- $\mathrm{BB}$ as shown in (Table 3 ). This indicates that the combined action of resveretrol and carnosol may more effective than that of any one of the compound, this has been discussed in HEX docking. The experimental analysis was in fairly good agreement with molecular docking findings ${ }^{[18]}$. 


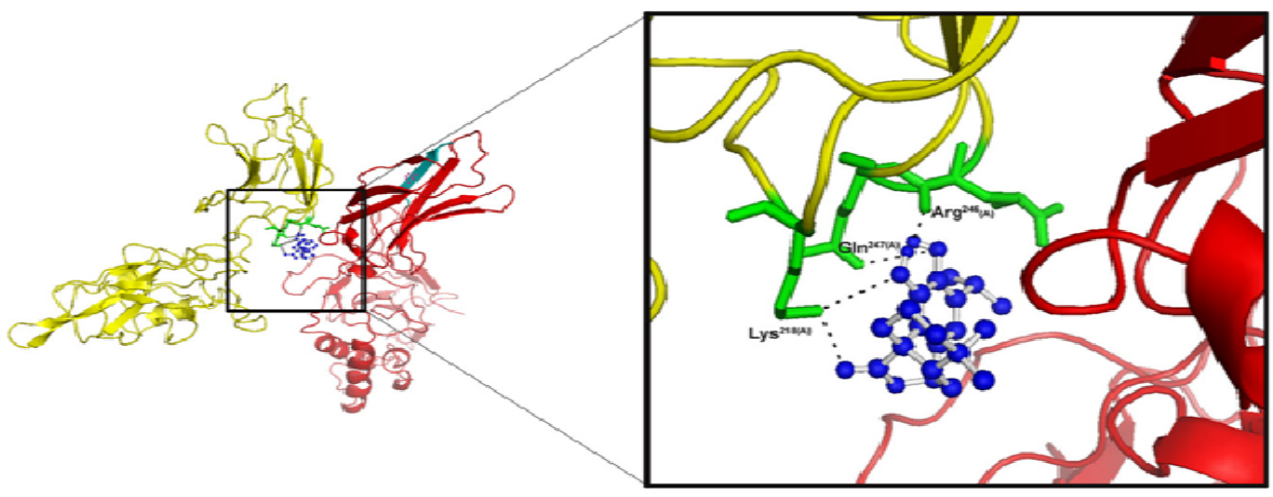

Figure 6a: RESL binding interaction with DNA binding residues (cyan color sticks) of p50 chain (Chain B) of NF- $\mathrm{B}$
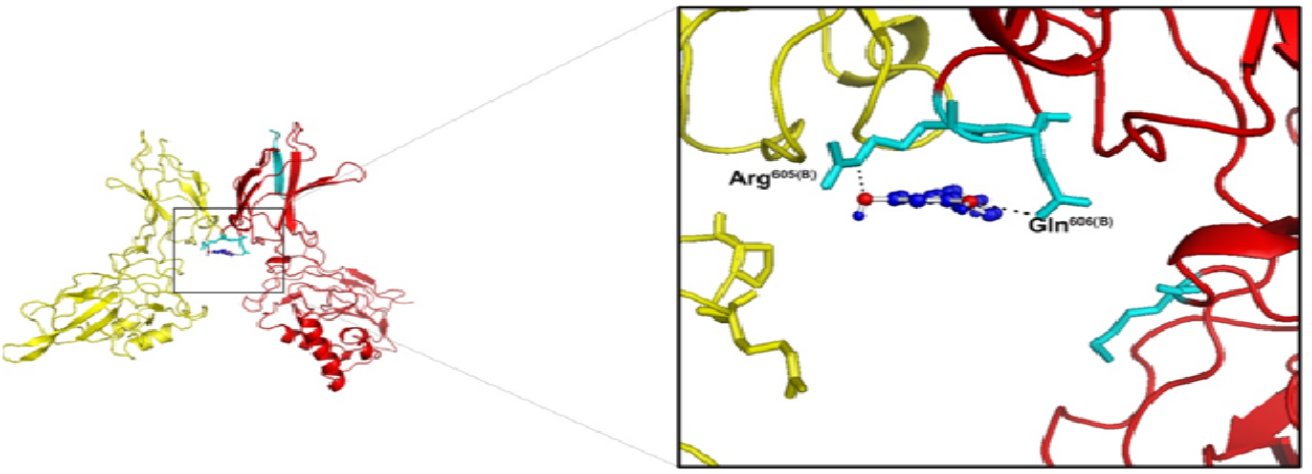

Figure 6b: CAR binding interaction with DNA binding residues (green color sticks) of p65 chain (Chain A) of NF- $\mathrm{BB}$

\section{Docking of DNA with Complex NF-кB-resveretrol-carnosol}

The energy minimized crystal structure were taken for further hex docking studies, minimized structure of NF- $\mathrm{B}$ docked with DNA molecule using Hex 1.0 server. The Hex results reveal that the DNA tightly interact with both chains of NF- $\kappa B$ p65/ p50 Heterodimer at the DNA binding sites as similar to the experimental results and it release the maximum total energy value of - 9.978486e K.joules (Table 4). The docked structure was superposed in experimental structure the RMS deviation shown 0.0 nm. The docked complex of resveretrol NF- $\kappa B$, redocked with DNA it shows decrease in the total energy value to - 2.006070e K.joules due to resveretrol involved in strong H-bond interaction with DNA binding residues of NF- $\kappa \mathrm{B}$ (Figure 7c). The docked complex of carnosol NF- $\kappa \mathrm{B}$, redocked with DNA it shows decrease in the total energy value to $-2.043593 \mathrm{e}$ K.joules; due to carnosol involved in strong H-bond interaction with DNA binding residues of NF- $\kappa B$. The Hex docking ${ }^{[19]}$ results reveal that the resveretrol can slightly decrease the binding ability of DNA with NF- $\mathrm{BB}$. As similar above NF- $\kappa \mathrm{B}-$ resveretrol-carnosol complexes was redocked with DNA. The results shows that due to conformational changes in NF- $\kappa$ B by binding of resveretrol and carnosol complex at the DNA binding region, the DNA able to form less interaction with of NF- $\kappa$ B (Figure 7c) and it release the energy value - 1.085541e K.joules. The docking hypothesis clearly demonstrate during binding of resveretrol- carnosol complex to NF- $\mathrm{BB}$ at DNA binding site, resveretrol-carnosol complex prevent or decrease the binding affinity of NF- $\kappa$ B toward the DNA.

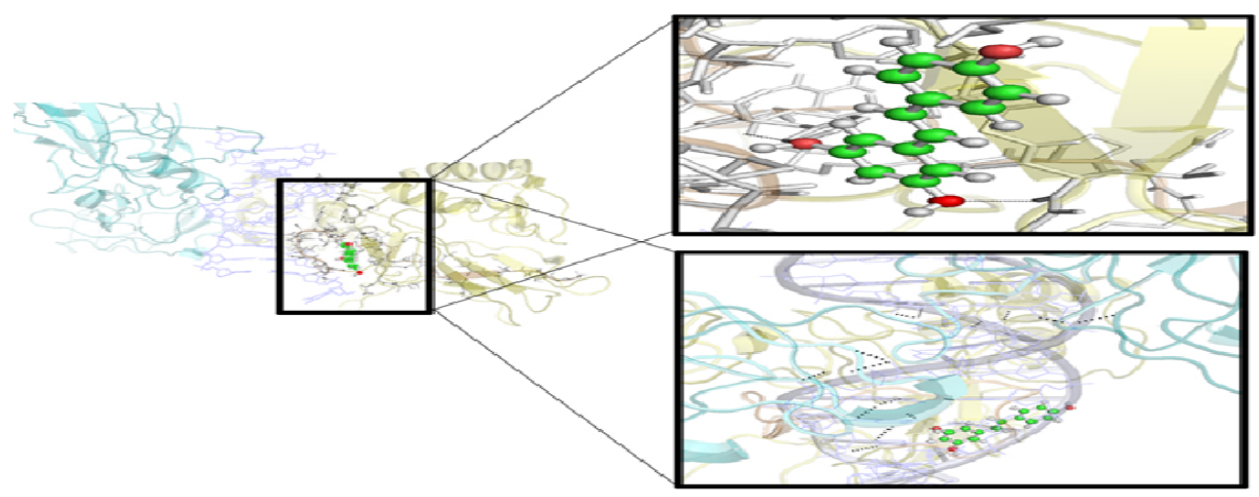

Figure 7a: The DNA interaction with NF- $\mathrm{kB}-$ RESL complex, Zoom top view represents the interaction of RESL at DNA binding region (Yellow color stick (p65) Cyan color stick (p50)) of NF- $\mathrm{kB}$. The Zoom bottom view shows the binding interaction of DNA (Black color ribbons) with the complex of NF- $\mathrm{BB}-\mathrm{RESL}$. 


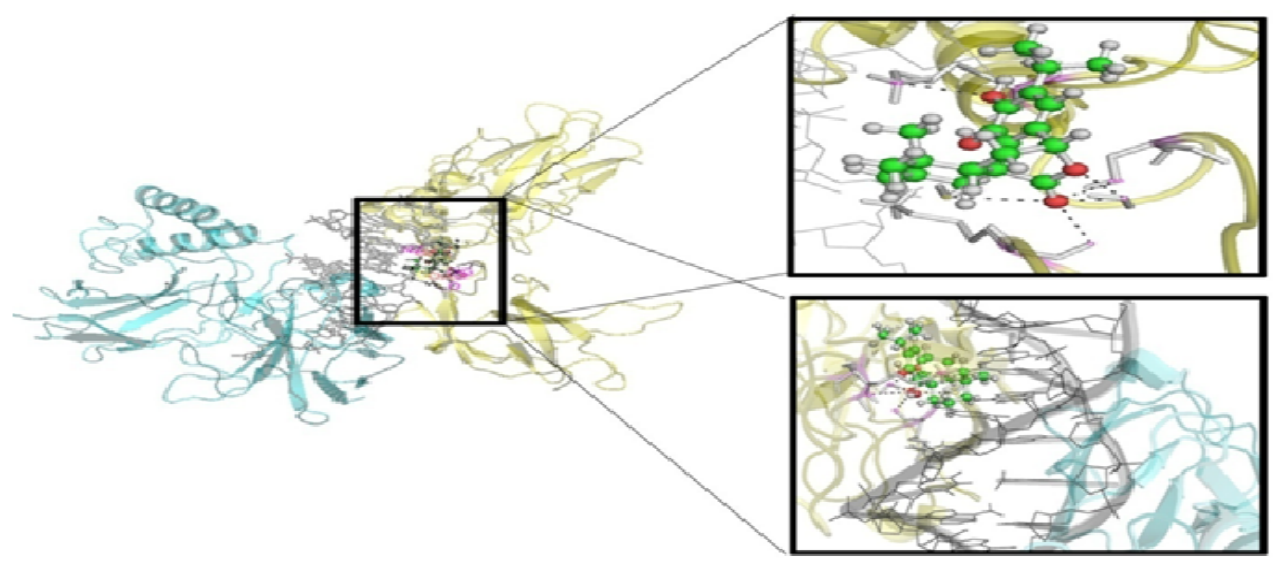

Figure 7b: The DNA interaction with NF-кB-CAR complex; Zoom top view represents the interaction of CAR at DNA binding region (Grey

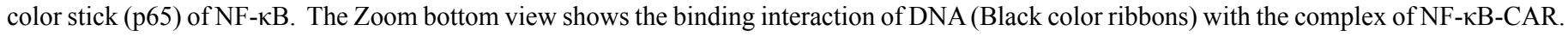

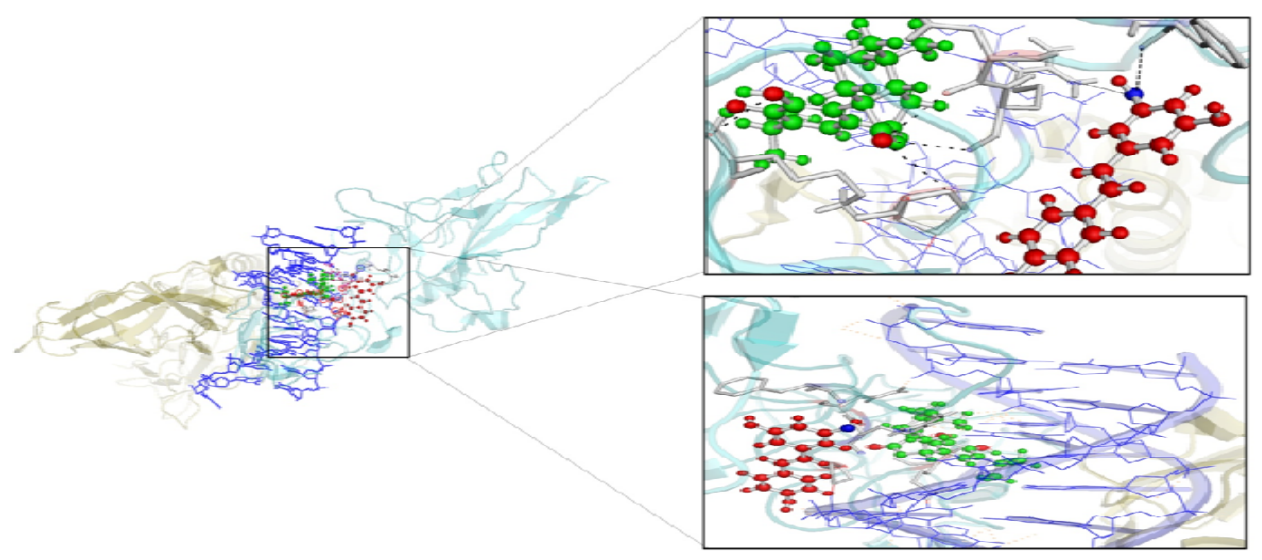

Figure 7c: The DNA interaction with NF-kB-RES -CAR complex; Zoom top view represents the interaction of RESL-CAR at DNA binding region (Greay color stick (p65) Cyan color stick (p50)) of NF- $\mathrm{kB}$. The Zoom bottom view shows the binding interaction of DNA (Blue color ribbons with lines) with the complex of NF-kB-RES-CAR.

\section{Conclusion}

As per the binding energies, P50 monomer has more effective binding interaction with carnosol by providing negative binding charge of $-6.15 \mathrm{~K} \mathrm{cal} / \mathrm{mol}$, than that of binding interaction with resveretrol having binding charge of $-1.5 \mathrm{~K} \mathrm{cal} / \mathrm{mol}$. Similarly in case of p 65 the binding charges of carnosol and resveretrol are $-3.10 \mathrm{~K} \mathrm{cal} / \mathrm{mol}$ and $-0.89 \mathrm{~K} \mathrm{cal} / \mathrm{mol}$ respectively indicates that p65 has less affinity than that of p50 towards carnosol. This predicts that the first choice goes to p50 monomer which is showing high inhibition binding energy by carnosol, this conclude that there is no formation of p50-p50 and p65-p50 (NF- $\mathrm{BB}$ ) dimers, further there is no anti-apoptotic signals occur. This has to be proving in my in-vitro animal cell culture work. If monomers are not inhibited either with carnosol nor resveretol there is much more possibility to inhibit dimmer (p65-p50). The docking energies are more effective evidence towards p50-p65 dimer with carnosol and resveretrol showed in table.3. Based on the above data, we predicting that p50 monomer and p65-p50 dimer are more effectively inhibited by carnosol then resveretrol. The docking poses of all these have been shown in (Figure 6). In case of complex docking in HEX, the docking results of p65-p50 resveretrol-carnosol complexes with DNA, shows higher order of inhibition and less binding interaction energies with DNA. The order of inhibition for dimer i.e. for p65-p50 resveretrol-carnosol complex when docked with DNA showing low binding energy than p65-p50-carnosol complex followed by p65-p50-resveretrol complex, the binding energies are depicted in (Table 4). If the binding energy decreases the affinity between p65-p50 and DNA decreases, finally there are no anti-apoptotic signals. In our in-silico prediction we clearly observed that combined inhibitory action of carnosol and resveratrol is more effective than independent action on NF- $\mathrm{KB}$. In case of comparative between carnosol and resveratrol, cornosol is more effective than resveratrol in inhibition of NF-kB. This work has to be further extended to in-vitro evidence. 
Table 4: Hex Docking results of NF-KB-RESL (P50-P65-RESL) and Carnosol with DNA (*Most of the key DNA binding interactions, such as the recognition with His364, Arg356 and Arg354 of p50, and Arg35 and Arg33 of p65 (RelA)) (stroud et al., 2009)

\begin{tabular}{|c|c|c|c|}
\hline S.No. & Molecules & E-total KJ/Mol & Amino acid in Interaction \\
\hline 1 & NF-кB-DNA & -9.978486 & $\begin{array}{l}\operatorname{Arg}^{33}(\mathrm{~A}), \operatorname{Arg}^{35}(\mathrm{~A}), \operatorname{Tyr}^{36}(\mathrm{~A}), \mathrm{Glu}^{39}(\mathrm{~A}), \operatorname{Lys}^{123}(\mathrm{~A}), \operatorname{Arg}^{187}(\mathrm{~A}), \operatorname{Gln}^{220}(\mathrm{~A}), \operatorname{Lys}^{221}(\mathrm{~A}), \operatorname{Arg}^{246}(\mathrm{~A}), \\
\operatorname{Arg}^{247}(\mathrm{~A}), \operatorname{Arg}^{354}(\mathrm{~B}), \operatorname{Arg}^{356}(\mathrm{~B}), \operatorname{Tyr}^{357}(\mathrm{~B}), \operatorname{His}^{364}(\mathrm{~B}), \operatorname{Lys}^{444}(\mathrm{~B}), \operatorname{Lys}^{539}(\mathrm{~B}), \operatorname{Gln}^{574}(\mathrm{~B}), \operatorname{Arg}^{605}(\mathrm{~B}) * \\
\operatorname{and}^{*} \operatorname{Gln}^{606}(\mathrm{~B})^{*} \text {. }\end{array}$ \\
\hline 2 & $\begin{array}{l}\text { NF-кB-RESL Com- } \\
\text { plex with DNA }\end{array}$ & -2.006070 & $\begin{array}{l}\operatorname{Arg}^{33}(\mathrm{~A})^{*}, \operatorname{Arg}^{35}(\mathrm{~A})^{*}, \operatorname{Tyr}^{36}(\mathrm{~A}), \operatorname{Cys}^{38}(\mathrm{~A}), \mathrm{Glu}^{39}(\mathrm{~A}), \operatorname{Arg}^{41}(\mathrm{~A}), \operatorname{Lys}^{123}(\mathrm{~A}), \operatorname{Asn}^{155}(\mathrm{~A}), \operatorname{Arg}^{187}(\mathrm{~A}), \\
\mathrm{Gln}^{220}(\mathrm{~A}), \operatorname{Arg}^{246}(\mathrm{~A}), \operatorname{Arg}^{354}(\mathrm{~B})^{*}, \operatorname{Arg}^{356}(\mathrm{~B})^{*}, \operatorname{His}^{364}(\mathrm{~B})^{*}, \mathrm{Gly}^{365}(\mathrm{~B}), \operatorname{Val}^{442}(\mathrm{~B}), \operatorname{Thr}^{443}(\mathrm{~B}), \mathrm{Ly}- \\
\mathrm{s}^{444}(\mathrm{~B}), \operatorname{Lys}^{541}(\mathrm{~B}), \operatorname{Pro}^{543}(\mathrm{~B}), \operatorname{Lys}^{575}(\mathrm{~B}), \text { and } \operatorname{Gln}^{606}(\mathrm{~B})^{*} .\end{array}$ \\
\hline 3 & $\begin{array}{l}\text { NF-kB CAR com- } \\
\text { plex with DNA }\end{array}$ & -2.043593 & $\begin{array}{l}\operatorname{Arg}^{33}(\mathrm{~A})^{*}, \operatorname{Arg}^{35}(\mathrm{~A})^{*}, \operatorname{Tyr}^{36}(\mathrm{~A}), \mathrm{Cys}^{38}(\mathrm{~A}), \mathrm{Glu}^{39}(\mathrm{~A}), \operatorname{Arg}^{41}(\mathrm{~A}), \operatorname{Lys}^{123}(\mathrm{~A}), \operatorname{Asn}^{155}(\mathrm{~A}), \operatorname{Arg}^{187}(\mathrm{~A}), \\
\operatorname{Arg}^{354}(\mathrm{~B})^{*}, \operatorname{Arg}^{356}(\mathrm{~B})^{*}, \operatorname{Tyr}^{357}(\mathrm{~B}), \operatorname{Cys}^{359}(\mathrm{~B}), \operatorname{His}^{364}(\mathrm{~B})^{*}, \mathrm{Gly}^{365}(\mathrm{~B}), \operatorname{Val}^{442}(\mathrm{~B}), \operatorname{Thr}^{443}(\mathrm{~B}), \mathrm{Ly}- \\
\mathrm{s}^{541}(\mathrm{~B}), \mathrm{Lys}^{575}(\mathrm{~B}) \text { and } \operatorname{Arg}^{605}(\mathrm{~B})^{*}\end{array}$ \\
\hline 4 & $\begin{array}{l}\text { NF-KB-RES-CAR } \\
\text { complex with DNA }\end{array}$ & -1.085541 & $\begin{array}{l}\operatorname{Arg}^{35}(\mathrm{~A})^{*}, \operatorname{Tyr}^{36}(\mathrm{~A}), \mathrm{Cys}^{38}(\mathrm{~A}), \operatorname{Glu}^{39}(\mathrm{~A}), \operatorname{Arg}^{41}(\mathrm{~A}), \operatorname{Arg}^{187}(\mathrm{~A}), \operatorname{Arg}^{246}(\mathrm{~A}), \operatorname{Arg}^{354}(\mathrm{~B})^{*}, \operatorname{Tyr}^{357}(\mathrm{~B}) \text {, } \\
\mathrm{Cys}^{359}(\mathrm{~B}), \operatorname{His}^{364}(\mathrm{~B})^{*}, \operatorname{Gly}^{365}(\mathrm{~B}), \operatorname{Val}^{442}(\mathrm{~B}), \operatorname{Thr}^{443}(\mathrm{~B}), \operatorname{Lys}^{572}(\mathrm{~B}), \operatorname{Gly}^{574}(\mathrm{~B}), \operatorname{Lys}^{575}(\mathrm{~B}) \text {, and Gl- } \\
\mathrm{n}^{606}(\mathrm{~B})^{*} .\end{array}$ \\
\hline
\end{tabular}

\section{Conflict of Interest}

Authors do not have conflict of interest.

\section{Acknowledgements}

We duly acknowledge Indian Council for Medical Research (ICMR), Govt. of India for providing Research Associate (RA) no. 45/20/2011-BMS/BIF dated 15/3/12. This work was supported by the core grant of DBT-Bioinformatics Facitily Centre (DBT$\mathrm{BIF})$.

\section{References}

1. Ho, C.T., Ferraro, T., Chen, Q., et al. Phytochemicals in teas and rosemary and their cancer preventive properties. In food Phytochemicals for cancer prevention 2. (1994) American Chemical Society Symposium Series 547: 2-19.

2. Johnson, J.J. Carnosol: A promising anti-cancer and anti-inflammatory agent. (2011) Cancer Lett 305(1): 1-7.

3. Farina, A., Ferranti, C., Marra, C. An improved synthesis of resveratrol. (2006) Nat Prod Res 20(3): 247-252.

4. Trantas, E., Panopoulos, N., Ververidis, F. Metabolic engineering of the complete pathway leading to heterologous biosynthesis of various flavonoids and stilbenoids in Saccharomyces cerevisiae. (2009) Metab Eng 11(6): 355-366.

5. https://en.wikipedia.org/wiki/Daily_News_and_Analysis.

6. Guttridge, D.C., Albanese, C., Reuther, J.Y., et al. NF- $\kappa B$ controls cell growth and differentiation through transcriptional regulation of cyclin D1. (1999) Mol Cell Biol 19(8): 5785-5799.

7. Sovak, M. Grape Extract, Resveratrol, and Its Analogs: A Review. (2001) J Med Food 4(2): 93-105.

8. Nakshatri, H., Bhat-Nakshatri, P., Martin, D.A., et al. Constitutive activation of NF-kappaB during progression of breast cancer to hormone-independent growth. (1997) Mol Cell Biol 17(7): 3629-3639.

9. Morris G.M., Goodsell D.S., Halliday R.S., et al. Automated docking using a Lamarckian genetic algorithm and an empirical binding free energy function. (1998) J Comput Chem 19: 1639-1662.

10. Wiederstein, M., Sippl, M.J. Prosa-Web: interactive web service for the recognition of errors in three dimensional structures of proteins. (2007) Nucleic Acids Res.

11. Laskowski, R.A., Chistyakov, V.V., Thornton, J.M. PDBsum more: new summaries and analyses of the known 3D structures of proteins and nucleic acids. (2005) Nucleic Acids Res 33: D266-D268.

12. Schuettelkopf, A.W., Van Aalten, D.M. PRODRG a tool for high-throughput crystallography of protein-ligand complexes. (2004) Acta Crystallogr D Biol Crystallogr 60(8): 1355-1363.

13. Goodford, P.J. A computational-procedure for determining energetically favorable binding-sites on biologically important macromolecules. (1985) J Med Chem, 28(7): 849-857.

14. Laskowski, R.A., Luscombe, N.M., Swindells, M.B., et al. Protein clefts in molecular recognition and function. (1996) Protein Sci 5(12): $2438-2452$.

15. Pisabarro, M.T., Ortiz, A.R., Serrano, L. et al. Homology modeling of the Abl-SH3 domain. (1994) Proteins 20(3): 203-215.

16. Chaitanya, M., Babajan, B., Anuradha, C.M., et al. Exploring the molecular basis for selective bind ing of Mycobacterium tuberculosis Asp kinase toward its natural substrates and feedback inhibitors: a docking and molecular dynamics study. (2010) J Mol Model 16(8): $1357-1367$.

17. Madhusudana, P., Babajan, B., Chaitanya, M., et al. Molecular Characterization of Mtb-OMP decarboxylase by modeling, docking and dynamic studies. (2012) Interdiscip Sci 4(2): 142-152.

18. Piccagli, L., Fabbri, E., Borgatti, M., et al. Docking of molecules identified in bioactive medicinal plants extracts into the p50 NF-kappaB transcription factor: correlation with inhibition of NF-kappaB/DNA interactions and inhibitory effects on IL-8 gene expression. (2008) BMC Struct Biol 8: 38 .

19. Macindoe, G., Mavridis, L., Venkatraman, V., et al., HexServer: an FFT-based protein docking server powered by graphics processors. (2010) Nucleic Acids Res 38: W445-W449.

Ommega Online Publisher

Bioinformatics, Proteomics and Immaging Analysis

Short Title : Bioinfo Proteom Img Anal
ISSN: 2381-0793

E-mail : bioinfo@ommegaonline.org

website: www.ommegaonline.org 